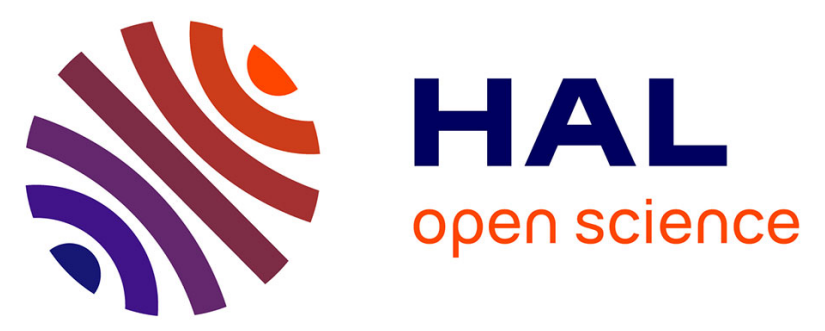

\title{
LES Study of Transverse Acoustic Instabilities in a Swirled Kerosene/Air Combustion Chamber
} Abdulla Ghani, Thierry Poinsot, Laurent Y.M. Gicquel, J.D. Müller

\section{To cite this version:}

Abdulla Ghani, Thierry Poinsot, Laurent Y.M. Gicquel, J.D. Müller. LES Study of Transverse Acoustic Instabilities in a Swirled Kerosene/Air Combustion Chamber. Flow, Turbulence and Combustion, 2016, vol. 96 (n. 1), pp. 207-226. 10.1007/s10494-015-9654-9 . hal-01272073

\section{HAL Id: hal-01272073 https://hal.science/hal-01272073}

Submitted on 10 Feb 2016

HAL is a multi-disciplinary open access archive for the deposit and dissemination of scientific research documents, whether they are published or not. The documents may come from teaching and research institutions in France or abroad, or from public or private research centers.
L'archive ouverte pluridisciplinaire HAL, est destinée au dépôt et à la diffusion de documents scientifiques de niveau recherche, publiés ou non, émanant des établissements d'enseignement et de recherche français ou étrangers, des laboratoires publics ou privés. 


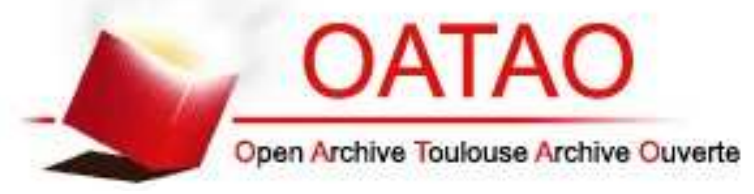

\section{Open Archive TOULOUSE Archive Ouverte (OATAO)}

OATAO is an open access repository that collects the work of Toulouse researchers and makes it freely available over the web where possible.

This is an author-deposited version published in : http://oatao.univ-toulouse.fr/ Eprints ID : 15119

To link to this article : DOI 10.1007/s10494-015-9654-9

URL : http://dx.doi.org/10.1007/s10494-015-9654-9

To cite this version : Ghani, Abdulla and Poinsot, Thierry and

Gicquel, Laurent Y.M. and Müller, J.-D. LES Study of Transverse

Acoustic Instabilities in a Swirled Kerosene/Air Combustion Chamber. (2016) Flow Turbulence and Combustion, vol. 96 (n 1). pp. 207-226.

ISSN 1386-6184

Any correspondance concerning this service should be sent to the repository administrator: staff-oatao@ listes-diff.inp-toulouse.fr 


\title{
LES Study of Transverse Acoustic Instabilities in a Swirled Kerosene/Air Combustion Chamber
}

\author{
Abdulla Ghani ${ }^{1}$. Thierry Poinsot ${ }^{2} \cdot$ Laurent Gicquel $^{1}$. \\ J.-D. Müller ${ }^{3}$
}

\begin{abstract}
LES is used to study self-excited transverse modes in an atmospheric, square combustor ( $\bar{p}=1$ bar). Simulations over a range of different mass flow rates show that transverse modes are present for all cases and exhibit varying RMS pressure amplitudes up to 0.4 bar. Analysis of LES results shows that transverse modes are due to a lock-in mechanism between an hydrodynamic unstable mode typical of swirling flows (the PVC mode or Processing Vortex Core) and the cavity modes. A control method using damping compliant walls (named DCWs) is applied to control the acoustic mode in the LES and to characterize the PVC in the absence of acoustic forcing. This method shows that the highest pressure oscillations appear when the PVC frequency is close to the frequency of the first transverse acoustic mode. A 3D Helmholtz solver is then used to predict the stability limits obtained by 3D LES. To capture transverse modes, a new flame transfer function (FTF) formulation is derived where local heat release perturbations are controlled by the orthoradial acoustic velocity fluctuations. The FTF is measured in the LES and when it is included in the Helmholtz solver, it allows to recover the stability zones observed in the LES.
\end{abstract}

Keywords Combustion instability $\cdot$ Transverse modes $\cdot$ Swirling spray flame $\cdot$ Precessing vortex core

Abdulla Ghani

ghani@cerfacs.fr

1 CERFACS, 42 Avenue Gaspard Coriolis, 31057 Toulouse Cedex 01, France

2 CNRS - Institut de Mécanique des Fluides de Toulouse, 1 Allee du Professeur Camille Soula, 31400 Toulouse Cedex, France

3 Queen Mary University of London, Mile End Rd, London, England 


\section{Introduction}

Combustion instabilities are well-known phenomena, occurring in many combustion chambers where they represent both a considerable risk $[1,2]$ and an unsolved scientific problem. The combustion community has developed an intense activity to study longitudinal modes in combustion chambers [3-7] and more recently azimuthal modes in annular configurations [8-12]. O'Connor et al. [13] review the role of azimuthal modes in a single sector of annular combustors where the effect of an azimuthal mode can be mimicked by transverse modes. One class of instability, however, has received less attention (except in the rocket community): transverse modes where flames are coupled to acoustic modes propagating between the lateral walls of a combustor. These modes can appear in all types of combustion systems. In gas turbines, the most well known example of transverse modes is screech $[14,15]$ which can lead to a rapid destruction of engines in afterburners. But there are other examples [16] where these modes (which have higher frequencies than longitudinal oscillations) have been identified in the main chamber of gas turbines and where the physics of this instability remains mysterious. Transverse acoustic waves interacting with flames have been studied experimentally and numerically since 2009 [17-20] in forced configurations. The objective of the present work is to study self-excited transverse modes in a square laboratory combustion chamber using LES and an acoustic solver.

The combustor studied here is a swirled system operated at Onera [21] where a strong PVC (Precessing Vortex Core) develops. The interaction of the PVC and combustion instabilities has been the topic of many recent publications [22-29]. LES allows to capture the coupling between PVC and acoustics but also to study the PVC and acoustics separately by controlling the acoustic field. Here, a control system located on the combustor lateral walls is used to damp the transverse acoustic mode and to characterize the PVC alone for different mass flow rates: this is done using lateral compliant walls (called DCWs for Damping Compliant Walls). These flexible walls have a non-zero normal velocity and their impedance can be tuned to act as acoustic dampers. DCWs are a numerical representation of damping control techniques used for longitudinal instabilities $[30,31]$ which are extended here to control transverse modes.

Even if the DCWs method allows to decouple PVC and thermoacoustics and therefore to use LES to analyze each mechanism separately, no proper theoretical background exists today to predict transverse modes. For longitudinal modes, the most common stability model is the $n-\tau$ approach of [32] which links axial velocity perturbations with perturbations of heat release. For transverse modes the extension of Croccos's idea is unclear and there is no obvious reason to link heat release and velocity fluctuations. The present results suggest that an extended FTF formulation linking orthoradial (and not axial as in Crocco's model) velocity components and heat release can indeed be used to predict these modes. This approach is called T-FTF (for transverse flame transfer functions).

The paper is organized as follows: Section 2 presents the configuration which is a square laboratory-scale kerosene/air swirled combustor. Section 3 describes a study of the acoustic modes of the combustor, using a 3D Helmholtz solver [33, 34]. This first step allows to identify all chamber modes which may appear with combustion. The LES solver and the control technique are presented in Section 4. Section 5 describes the LES diagnostics used for transverse modes. In Section 6 the transverse mode limit cycle captured in the LES is studied. A new T-FTF model, adapted to transverse modes is presented in Section 7 and compared to LES data in terms of stability limits. 


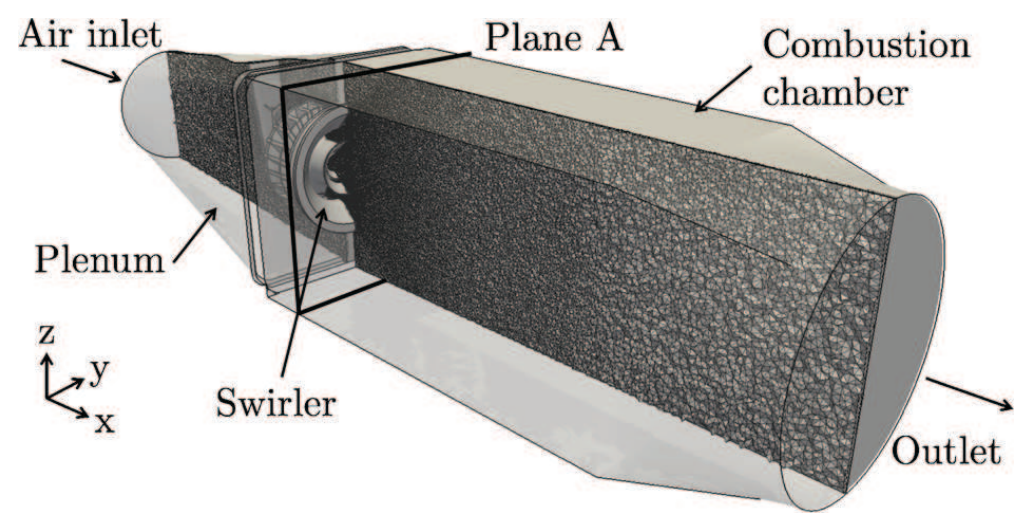

Fig. 1 Middle cut plane of the mesh in the computational domain. Plane A is located $15 \mathrm{~mm}$ downstream of the swirler outlet section

\section{Configuration}

The target configuration consists of a plenum and a rectangular combustion chamber fed by a multipoint swirler (Fig. 1). The chamber has a length of $0.31 \mathrm{~m}$ and a volume of approximately $0.006 \mathrm{~m}^{3}$. Height and width of the constant chamber section are equal $(0.12 \mathrm{~m})$. The swirler contains one radial and two axial stages (Figs. 2 and 3 left). The first axial stage swirls the flow in counter clockwise direction. The second axial stage forces the flow to turn in clockwise direction whereas the radial swirl movement turns again in counter clockwise direction. Kerosene is injected using a combination of pilot injector and multipoint fuel injection system with 24 holes. Details on the operating point are given in Section 4. Note that this configuration was initially mounted by Apeloig et al. [21] for flame transfer function measurements in the low- frequency range issuing longitudinal modes. The high-frequency range was not of interest when the experiments were performed. Numerical simulations were carried out after the experimental campaign was finished and the setup was dismantled so that no experimental evidence is providable in this study.

Fig. 2 Middle cut plane of the mesh showing the swirling device (proportions changed)

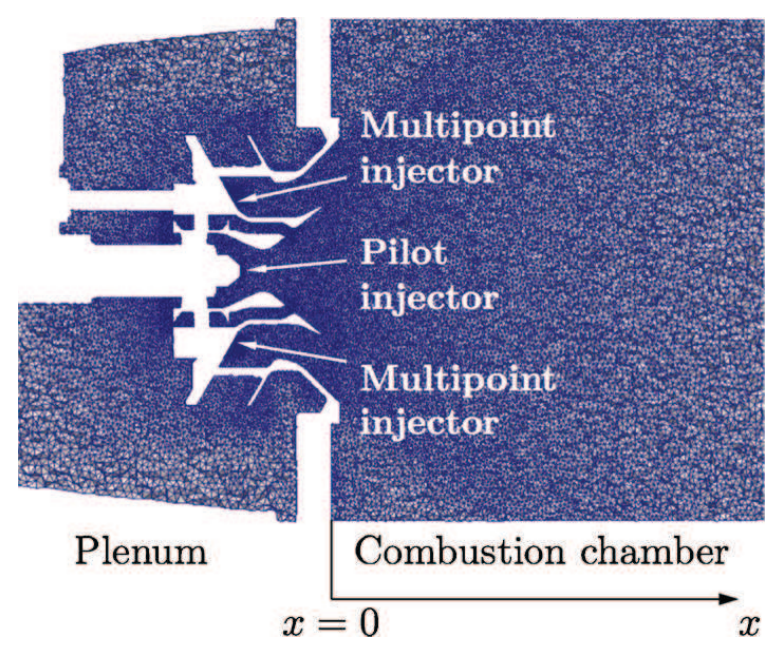




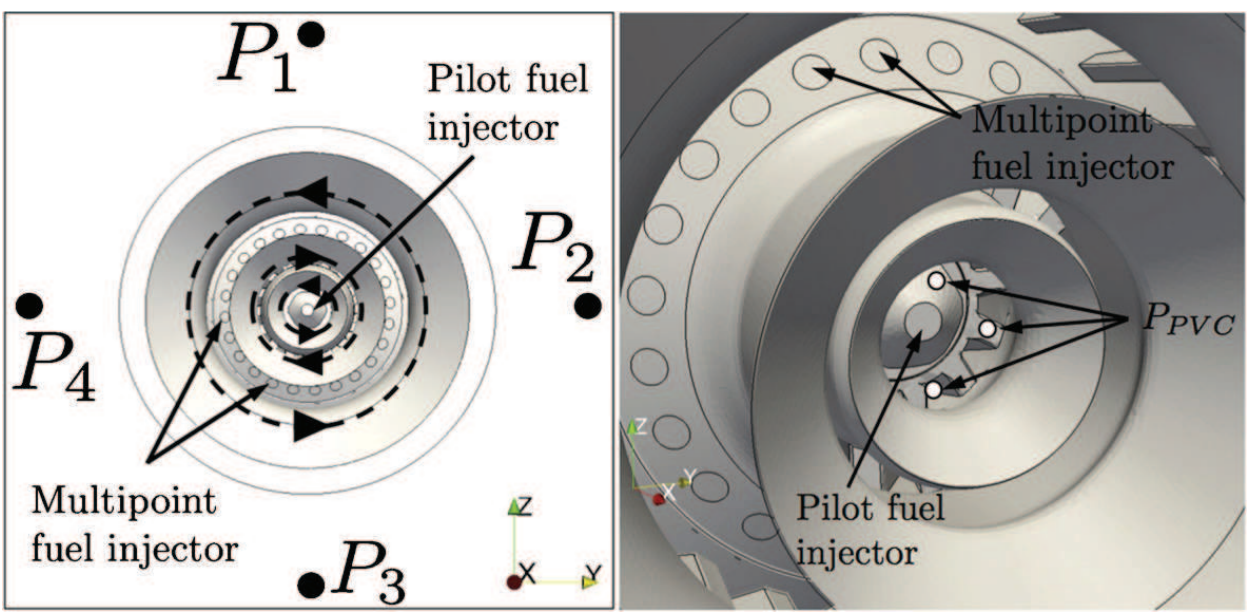

Fig. 3 Left: View from chamber exit to injection device. Swirler with flow direction of each stage. Location of pressure probes $P_{1}$ to $P_{4}$ and of fuel injection points. Right: Zoom to injector with positions of PVC probes

\section{Acoustic Modes of the Combustor Rig}

Since flame coupling with the acoustic cavity modes is expected, it is interesting to first compute the acoustic modes of the full combustor before starting LES. A Helmholtz solver called AVSP [33] is used for the complete geometry of Fig. 1. Assuming small perturbations and no active flames, the Helmholtz equation is derived from the linearized Euler equations as:

$$
\gamma p_{0} \nabla \cdot\left(\frac{1}{\rho_{0}} \nabla \hat{p}\right)+\omega^{2} \hat{p}=0
$$

where the variables $p_{0}, \hat{p}, \omega$ and $\gamma$ are the mean pressure, pressure amplitude $\left(p^{\prime}=\hat{p} e^{j \omega t}\right)$, pulsation and specific heat ratio, respectively. The outlet pressure is imposed $\left(p^{\prime}=0\right)$ whereas all other walls are zero velocity fluctuation boundaries $\left(u^{\prime}=0\right)$. Even though the unsteady activity of the flame is neglected in Eq. 1 by setting the RHS to zero, the mean effect of combustion is retained and $\rho_{0}$ includes the density changes due to combustion (temperature varies from $473 \mathrm{~K}$ in the fresh gases to $2090 \mathrm{~K}$ in the burnt gases). Here, a two-zone temperature field is used: unburnt in the plenum and burnt in the chamber. The computations were performed with variable values for specific heat ratio and mean pressure $p_{0}=1$ bar.

Table 1 gives the frequencies of the first three longitudinal and the first transverse mode of the chamber obtained by AVSP. Most of the other acoustic modes are plenum modes at frequencies higher than $3000 \mathrm{~Hz}$ for which the chamber activity is low. The structure

Table 1 Frequencies of the first four modes given by the Helmholtz solver and comparison with the mode frequency found in the LES

\begin{tabular}{llll}
\hline Mode name & Nature (Eigenvalue index) & Helmholtz solver $[\mathrm{Hz}]$ & LES $[\mathrm{Hz}]$ \\
\hline 1L & Single (1) & 351 & - \\
2L & Single (1) & 778 & - \\
3L & Single (1) & 1956 & - \\
1T-1L & Degenerate (2) & 3150 & 3075 \\
\hline
\end{tabular}



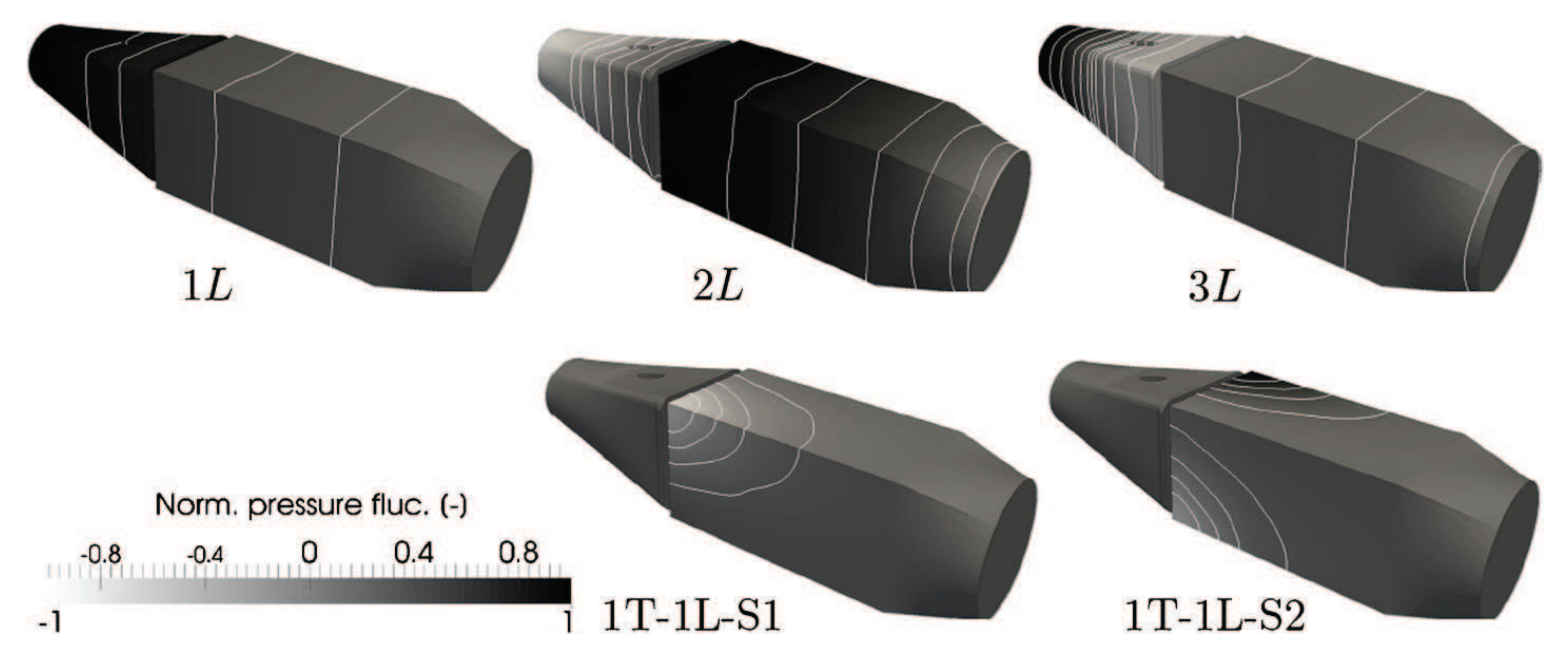

Fig. 4 The first three longitudinal chamber modes and the first tangential mode obtained by the Helmholtz solver displayed by normalized pressure fluctuations $\left(p^{\prime}=|\hat{p}| \cos (\arg (\hat{p}))\right)$. Mode frequencies are given in Table 1

of the modes (evidenced by the $p^{\prime}$ field) is complex but a few modes are especially interesting: three longitudinal modes are found at $351 \mathrm{~Hz}, 778 \mathrm{~Hz}$ and $1956 \mathrm{~Hz}$ (Fig. 4 top). These modes are not observed in the LES. The first transverse chamber modes (1T-1L) are found at $3150 \mathrm{~Hz}$ (Fig. 4 bottom). The $3150 \mathrm{~Hz}$ frequency is degenerate: two modes coexist with the same frequency. Similarly to azimuthal modes in annular chambers [35, 36], these modes can be described using a basis of two standing modes called 1T-1L-S1 and 1T-1L-S2 displayed in Fig. 4. Alternatively, another basis of modes can be used, corresponding to turning modes which can be obtained by a combination of 1T-1L-S1 and 1T-1L-S2 to obtain a clockwise turning mode 1T-1L-T1 or counter clockwise turning mode 1T-1L-T2. The structures of pressure fluctuations $p^{\prime}$ for these 4 modes are summarized in Fig. 5.

\section{Large Eddy Simulation Methodology}

\subsection{Numerical setup}

The operating point computed with LES corresponds to a case with preheated air at $473 \mathrm{~K}$ (air flow rate of $\dot{m}_{A i r}=100 \mathrm{~g} / \mathrm{s}$ ). Liquid kerosene is injected at a temperature of $293 \mathrm{~K}$ through the pilot $\left(\dot{m}_{F_{P}}=0.17 \mathrm{~g} / \mathrm{s}\right)$ and multi point system $\left(\dot{m}_{F_{M P}}=4.86 \mathrm{~g} / \mathrm{s}\right)$ containing 24 injection holes. The global equivalence ratio is $\phi=0.74$. This regime is the only one considered here because it produces a strong transverse mode.

Figure 1 shows the middle cut plane of the mesh: the fully unstructured mesh contains 18005356 tetrahedral elements and 3185744 nodes. Mesh refinements are displayed in Fig. 2 and concern mainly the swirling device. The time step is fixed at $\Delta t=6 \cdot 10^{-8} \mathrm{~s}$ which corresponds to a CFL number of 0.7 [37]. All boundaries are no-slip adiabatic walls except the inlet at the plenum and the outlet at the chamber exit where partially reflecting Navier-Stokes Characteristic Boundary Condition (NSCBC) formulations are used [38]. No turbulence is injected through the inlets since most of the turbulence is generated through the swirling device. 


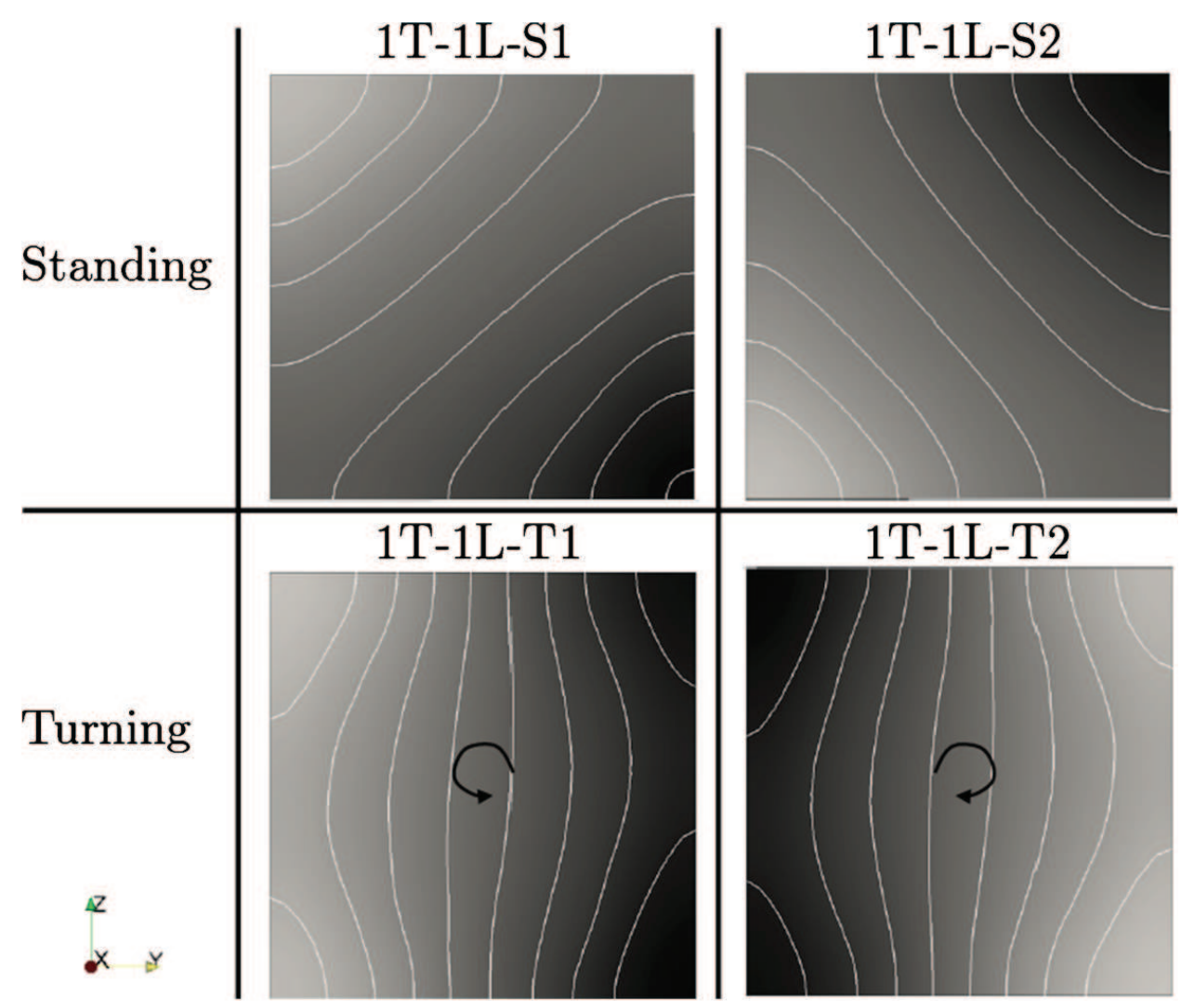

Fig. 5 First and second standing 1T-1L mode type (top) and their combinations of clockwise (CW) or counter clockwise $(\mathrm{CCW})$ turning 1T-1L modes (bottom). The y-z planes are obtained at the plane A position (Fig. 1). Same legend as in Fig. 4

LES is carried out using a fully compressible code [39, 40] which solves the reactive multi-species Navier-Stokes equations on unstructured grids [41]. A two-step TaylorGalerkin finite-element scheme [42] provides third-order accuracy in time and space. The sub-grid stress tensor is modeled by the Wale model described by Ducros et al. [43]. Chemical reactions are computed using a reduced two-step scheme for kerosene/air premixed flames [44]: six species are considered: $\mathrm{N}_{2}, \mathrm{O}_{2}, \mathrm{CO}, \mathrm{CO}_{2}, \mathrm{H}_{2} \mathrm{O}$ and kerosene. This scheme matches the results of the full scheme of Luche et al. [45] for kerosene/air flames in terms of flame speeds and adiabatic flame temperatures within an extended range of equivalence ratios $(0.6 \leq \phi \leq 2.0)$, pressures $(1.0 \leq P \leq 12.0 \mathrm{~atm})$ and fresh gas temperatures $\left(300 \leq T_{f} \leq 700 \mathrm{~K}\right)$. Liquid kerosene is injected using the mesoscopic Eulerian formalism [46-50], where the spray is considered as a continuous phase. The spray is supposed to be mono-disperse and a Sauter Mean Diameter $D_{32}=29 \mu \mathrm{m}$ is adopted at all injection points. This diameter provides the same volume to surface ratio as the entire spray. Realistic injection profiles are provided by the FIMUR methodology [48, 51, 52]. A hollow cone spray is imposed on the pilot fuel while a gaussian distribution is considered for each multipoint injection hole. To account for interactions between liquid and gas, a twoway coupling model [53] is used. The dynamic thickened flame model is used to describe flame/turbulence interactions [54-56] with the model of Charlette et al. [57] for the subgrid efficiency.

A convergence study was carried out on two additional meshes (2.6 M and 4.6 M grid points) and results are similar. Tests concerning sub-grid scale modeling [58] and flame wrinkling models [54] were also carried out: results differ only slightly and do not change the present conclusions. 


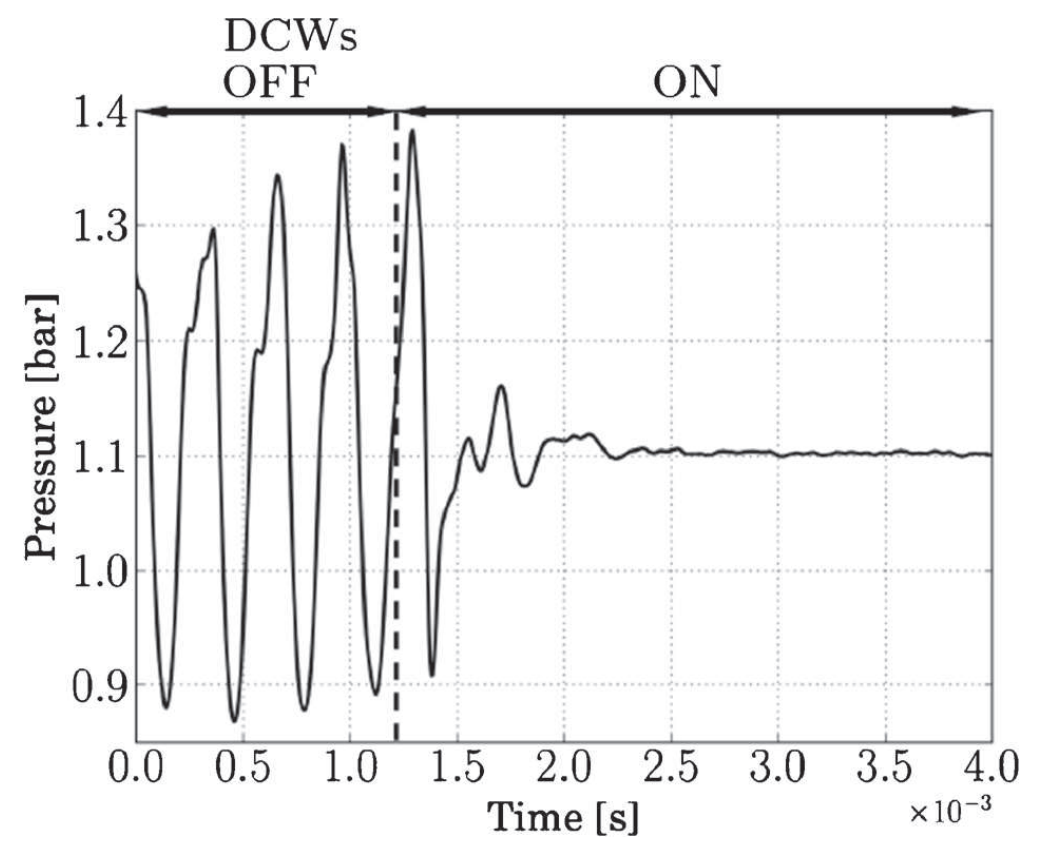

Fig. 6 From an unstable to a stable system by using DCWs. The system responds after 1 ms. Pressure is recorded at probe $P_{2}$ (Fig. 3)

\subsection{Damping compliant walls (DCWs)}

The next sections will show that LES captures transverse modes in this swirled burner and that they interact with the hydrodynamic modes of the flow and especially, the PVC. To study this interaction, it is interesting to control the acoustic modes by manipulating their reflection on the lateral walls. Here, a control method was used to suppress all transverse modes in the LES by modeling the walls on top and bottom of the combustion chamber (Fig. 1) as compliant walls which are not perfectly rigid and damp transverse acoustic waves. Numerically, the DCWs are 'soft' NSCBC walls. Their mean velocity is zero but not their fluctuation: a relaxation coefficient $\kappa$ is applied to the reflection coefficient:

$$
R=\frac{1}{1-i \omega / \kappa}
$$

In this work the relaxation coefficient is set to $\kappa=10000$ which yields a cut-off frequency of $f_{\text {cutt }}=800 \mathrm{~Hz}$. These partially reflecting boundaries behave like low-pass filters [59], so that acoustic waves above $f_{\text {cutt }}$ propagate out of the domain. The application of the method is presented in Fig. 6: starting from an unstable regime with a large fluctuation amplitude (from 0.8 bar to 1.3 bar), control with DCWs is switched on at an arbitrary instant $t=1.2 \mathrm{~s}$ and pressure oscillations are mitigated after $1 \mathrm{~ms}$. This technique does not require any mesh refinement near the walls where it is applied. The DCWs have been checked on different meshes and do not influence other flow characteristics.

\section{Diagnostics}

All pressure signals are recorded during the simulation at probes located in Fig. 3. The PVC frequency is obtained at the probe $P_{P V C}$ (Fig. 3 right) near the pilot injector marked in 
Fig. 7 Instantaneous snapshot of the PVC structure visualized by an iso-contour of the Q-criterion $Q_{\text {crit }}=1.5 e^{9} \mathrm{~s}^{-1}$

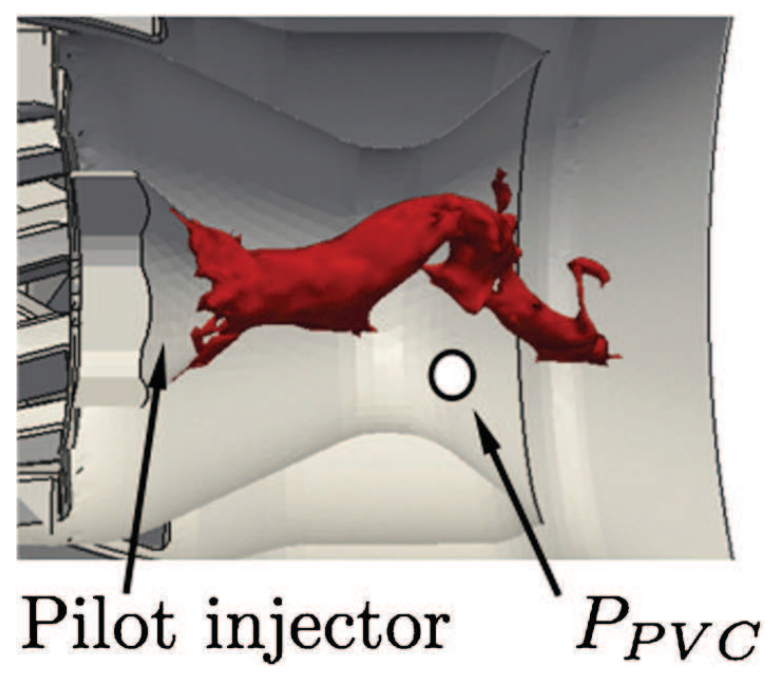

Fig. 7. The global heat release is calculated at each time step and integrated over the whole computational domain. Due to the fixed simulation time step, equidistant time signals are obtained with a sampling rate of $166 \mathrm{kHz}$.

The constant y-z section of the chamber (shown in Fig. 3) is divided in four equal quarters drawn in Fig. 8. The extracted quantities are integrated over each 3D quarter and represent their spatial average at the points denoted with $Q_{I}$ to $Q_{I V}$.

Extraction techniques such as proper orthogonal decomposition (POD) [24, 60, 61] or dynamic mode decomposition (DMD) [62, 63] are widely used to highlight coherent structures. Here, DMD is used based on 120 instantaneous 3D solutions collected every $1.6 e-5 \mathrm{~s}$. The data length corresponds to 6 periods of the mode oscillation frequency $f_{m}$. All results related here to DMD analysis are given for the most dominant frequencies.

\section{Limit Cycle Analysis}

\subsection{Pressure and heat release signal}

For the present condition $\left(\dot{m}_{A i r}=100 \mathrm{~g} / \mathrm{s}, \dot{m}_{F_{P}}=0.17 \mathrm{~g} / \mathrm{s}, \dot{m}_{F_{M P}}=4.86 \mathrm{~g} / \mathrm{s}\right)$, the LES signals rapidly exhibit a strong transverse acoustic activity. In a first step, the limit cycles obtained in LES are analyzed to identify the unstable modes. Pressure fluctuations (Fig. 9 top) show that the limit cycle is not perfectly harmonic and is modulated by a low frequency

Fig. 8 Schematic drawing of the $\mathrm{y}-\mathrm{z}$ chamber plane

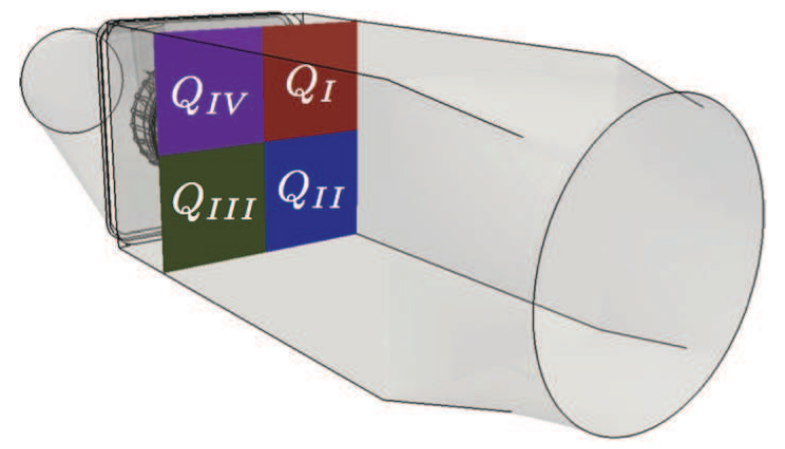


Fig. 9 Top: Pressure signal recorded at probe $P_{2}$. Bottom: Heat release fluctuations $q^{\prime}$ integrated in chamber quarter $Q_{I}$ and global heat release fluctuations integrated over the whole domain $Q_{g}^{\prime}$

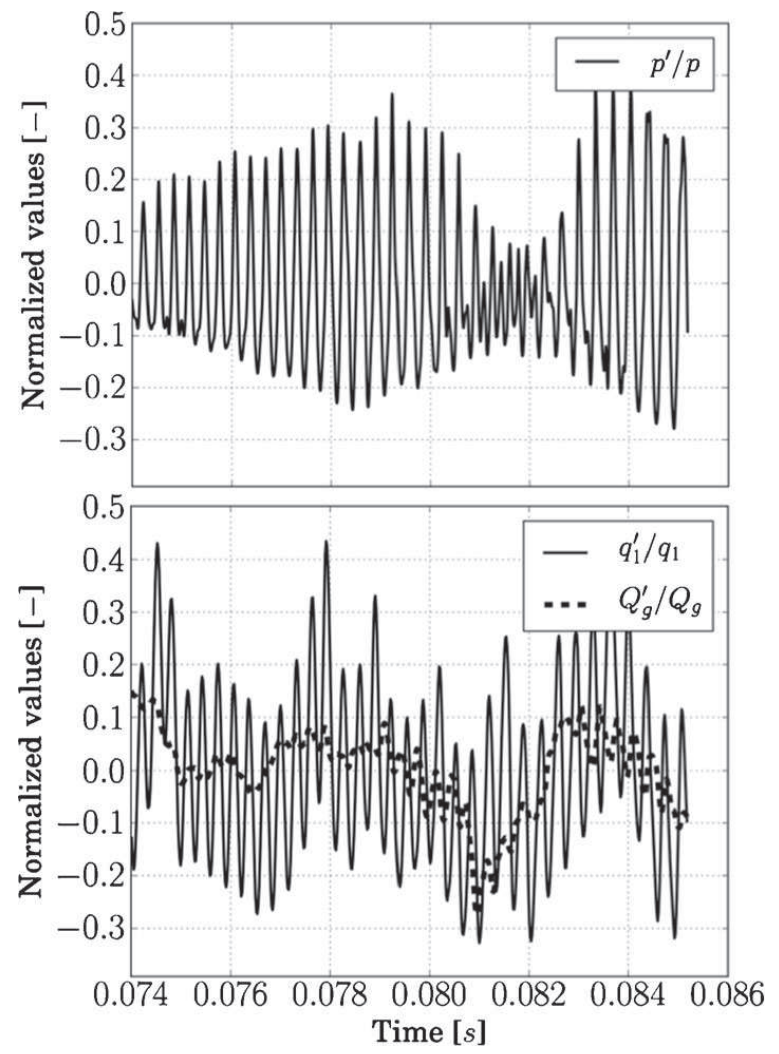

component $f_{i}$. The frequency of the transverse mode is $f_{m}=3075 \mathrm{~Hz}$ (Fig. 10 top). The amplitude of the fluctuations is very large $\left(p^{\prime} / \bar{p} \approx 0.3\right)$ corresponding to $180 \mathrm{~dB}$ [64] inside the chamber.

Figure 9 bottom shows the time evolution of global heat release fluctuations $Q_{g}^{\prime}$ in the chamber and heat release fluctuations $q_{1}^{\prime}$ integrated in one quarter chamber $Q_{I}$. The signal of the chamber quarter reveals heat release oscillations correlated with the transverse $3075 \mathrm{~Hz}$ mode while the global heat release is hardly influenced. This observation confirms the transverse nature of the mode: combustion pulsates at the transverse mode frequency when it is integrated over one quarter of the chamber. When averaged over the whole chamber, the transverse mode signature disappears indicating that the unsteady reaction rotates around the chamber while its volume averaged value is constant. The low-frequency modulation fi at about $50 \mathrm{~Hz}$ is due to the interaction of the PVC and the transverse mode as shown e.g. by Stein-berg et al. [25] and Moeck et al. [22]. Due to non-linearity of the system, this interaction frequency arises and impacts the flame but not in the longitudinal direction. It rather imposes a low-frequency rotating motion of the flame. Further analysis regarding this point were not carried out since the flame is mainly impacted by the transverse mode.

\subsection{Rayleigh criterion}

Even though the mode structure differs from longitudinal modes, its excitation mechanism follows the usual Rayleigh criterion if the analysis is performed on a quarter of the burner (Fig. 8) and not on the global chamber. Figure 11 displays pressure perturbations $\left(p^{\prime}\right)$, temperature fluctuations $\left(T^{\prime}\right)$ and unsteady heat release $\left(q^{\prime}\right)$ integrated in chamber quarter $Q_{I}$. Positive $q^{\prime}$ values (corresponding to unsteady combustion) are turning at the instability fre- 
Fig. 10 Top: Power spectral density of the pressure signal recorded at probe $P_{4}$. Bottom: Power spectral density of the heat release fluctuations integrated in quarter $Q_{I}$. The spectra are built using only the limit cycle time series $(0.074 \mathrm{~s}<t<0.084 \mathrm{~s}$ in Fig. 9.)

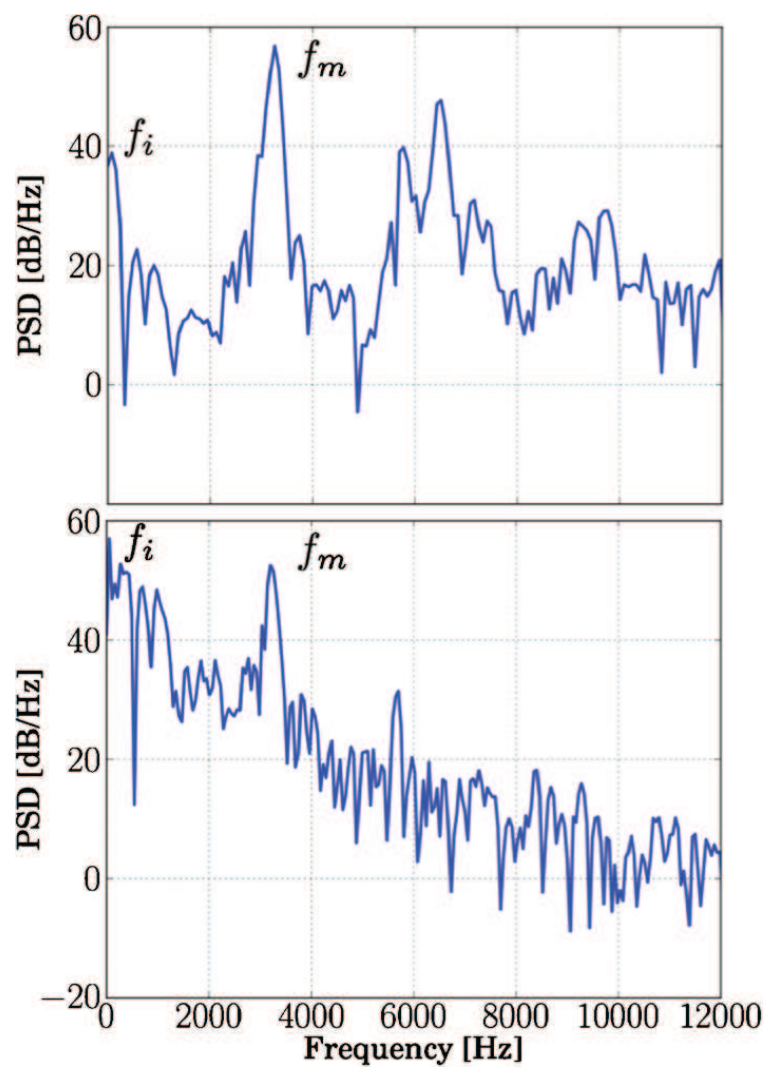

quency of the mode in phase with the pressure field: the Rayleigh criterion $[65,66]$ is satisfied.

The spatial Rayleigh distribution can be evaluated through 3D DMD data and is presented in Fig. 12: the outer flame region displays positive Rayleigh index values showing that pressure and heat release fluctuations are in phase. The near wall regions are the zones feeding energy into the transverse mode. The shear layer between the radial swirl jet and the center recirculation zone exhibits negative index values which indicate damping but this region is small compared to the in-phase zone as seen in the plane A cut.

\subsection{Mode structure}

DMD allows to visualize the mode pressure distribution at $3075 \mathrm{~Hz}$ during the limit cycle (Fig. 13). The mode structure corresponds to a combination of the two degenerate 1T-1L

Fig. 11 Fluctuations of pressure $p^{\prime}$, temperature $T^{\prime}$ and heat release $q^{\prime}$ during four transverse periods of the limit cycle. Data obtained in chamber quarter $Q_{I}$

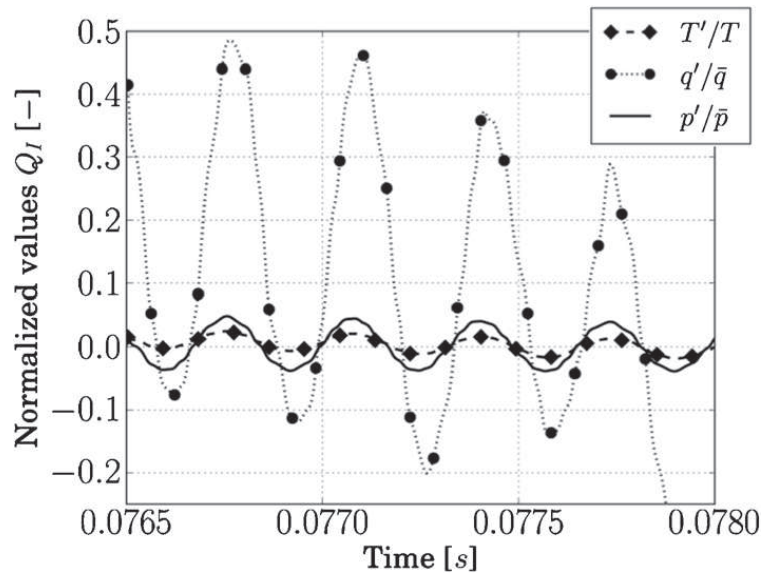



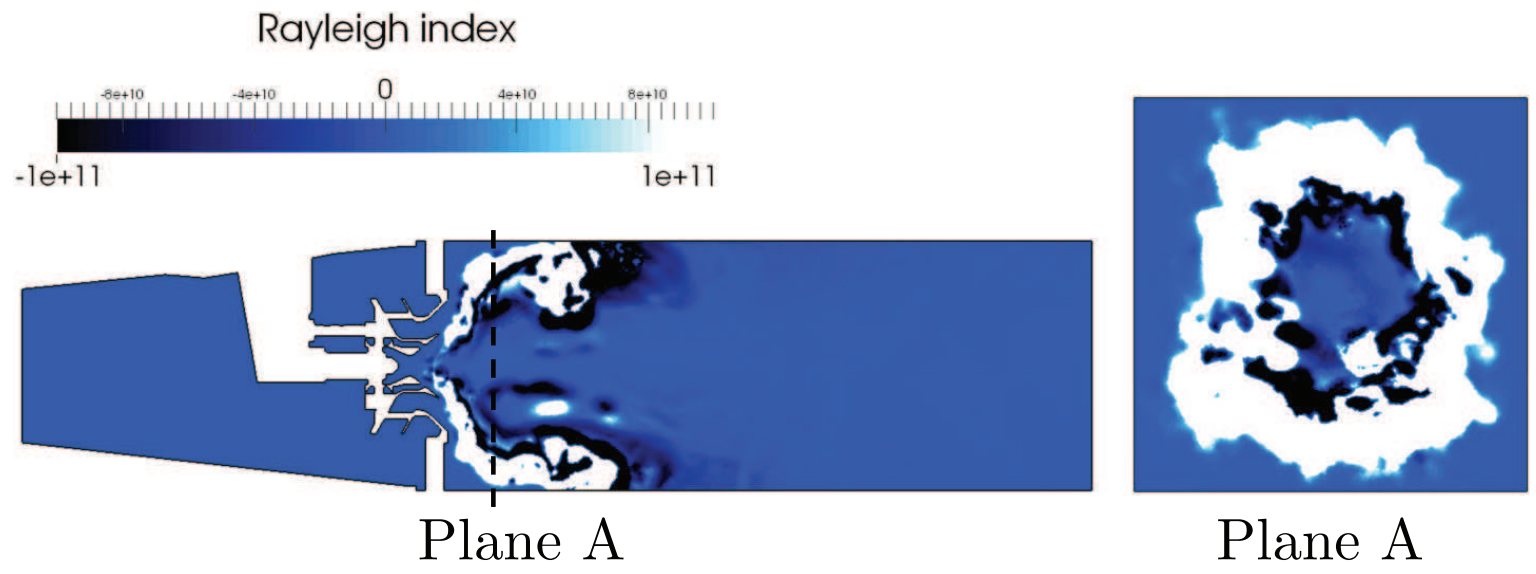

Fig. 12 Spatial distribution of the Rayleigh index in the mid cut plane and in plane A

modes predicted by the acoustic analysis (Fig. 5): pressure maxima are observed in the four corners of the chamber pointing to a $1 \mathrm{~T}-1 \mathrm{~L}-\mathrm{T} 1$ or $1 \mathrm{~T}-1 \mathrm{~L}-\mathrm{T} 2$ mode. The pressure argument (Fig. 13 bottom) confirms the rotating nature of the mode. To analyze the nature of the modes, a scaled mode indicator $C(t)$ is used [10, 35]:

$$
C(t)=\frac{1}{p_{\max }^{\prime}} \frac{1}{N} \sum_{k=1}^{N} p_{k}^{\prime}\left(\theta_{k}, t\right) e^{j \theta_{k}}
$$

where $\mathrm{N}$ denotes the number of the evenly spaced probes $P_{1}$ to $P_{4}$ (Fig. 3 left), $\theta_{k}$ their angular locations and $p_{k}^{\prime}$ the pressure fluctuations recorded at $P_{1}, P_{2}, P_{3}$ and $P_{4}$. The maximum pressure fluctuation observed during the growth phase $p_{\max }^{\prime}$ is used to scale $C(t)$. The phase of the indicator gives information about the mode type: a constant phase indicates a standing mode whereas an increasing (decreasing) phase refers to a clockwise (counter clockwise) rotation with $\omega t(-\omega t)[10,35]$. In Fig. 14 the indicator is applied only during the limit cycle from $t=0.07 \mathrm{~s}$ to $t=0.13 \mathrm{~s}$. The phase (Fig. 14 bottom) increases with time like $\omega t$, showing that the mode is mainly turning clockwise. This corresponds to the combined 1T-1L-T2 mode displayed in Fig. 5. Note that the phase can also remain constant over many

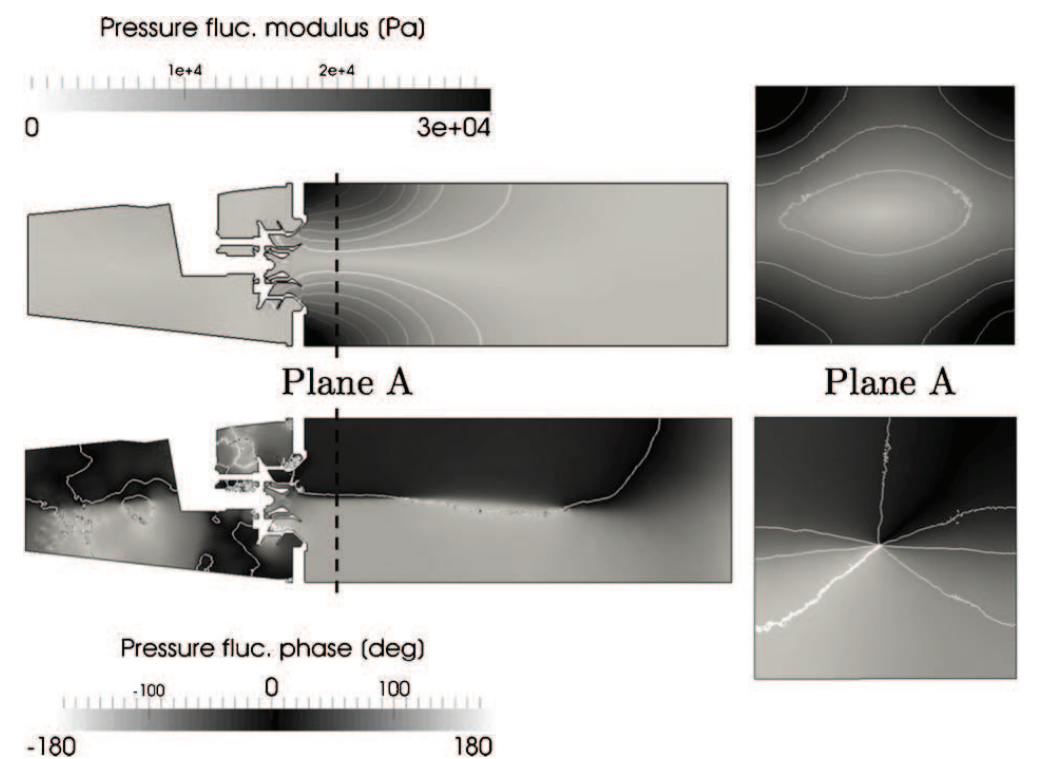

Fig. 13 Modulus (top) and phase (bottom) of pressure fluctuations obtained by DMD of the LES at $3075 \mathrm{~Hz}$ 
Fig. 14 Top: Mode indicator amplitude normalized by the maximum pressure. Bottom:

Phase of the mode indicator with the theoretical slope of $\omega t$ for the mode frequency

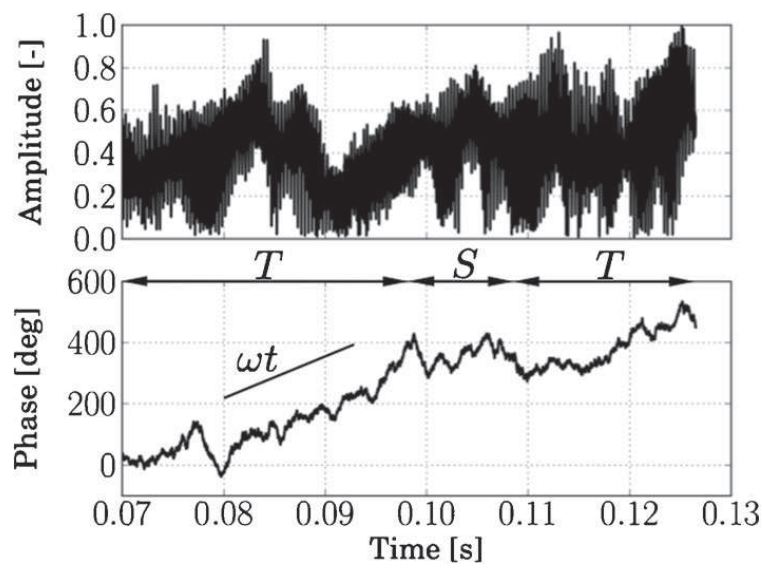

cycles (from $t=0.10 \mathrm{~s}$ to $t=0.11 \mathrm{~s}$ ), demonstrating that a standing mode can also take place. This pattern (turning $\rightarrow$ standing $\rightarrow$ turning) is repeatable and was observed in all simulations independently of the moment chosen to let the unstable mode grow. This result can be confirmed by a statistical method [10]: pressure and velocity time signals at probe $P_{2}$ are used to calculate the $A^{+}$and $A^{-}$waves in z-direction. Figure 15 shows the joint probability density function of these quantities: the $A^{-}$waves dominate meaning that waves are traveling in the clockwise direction. These results were also checked for the other probe positions. The mode typologies found by the indicator and the statistical method confirm the DMD results (Fig. 13).

\subsection{Instantaneous flow and flame dynamics}

The 1T-1L-T2 turning mode (Figs. 5 and 13) controls the flow field in Fig. 16: three different instants of the pressure oscillation amplitude are shown: maximal at $\pi / 2$, zero at $\pi$ and minimal at $3 \pi / 2$. High vertical velocities are encountered thus influencing the center recirculation zone (CRZ) displayed by a axial velocity contours. The recirculation zone sways from side to side as observed in experiments where swirling flames have been placed in transverse acoustic fields [19, 67]. This periodic, in-phase motion of the flame

Fig. 15 Joint probability density function of the waves $A^{+}$and $A^{-}$evaluated at probe $P_{2}$

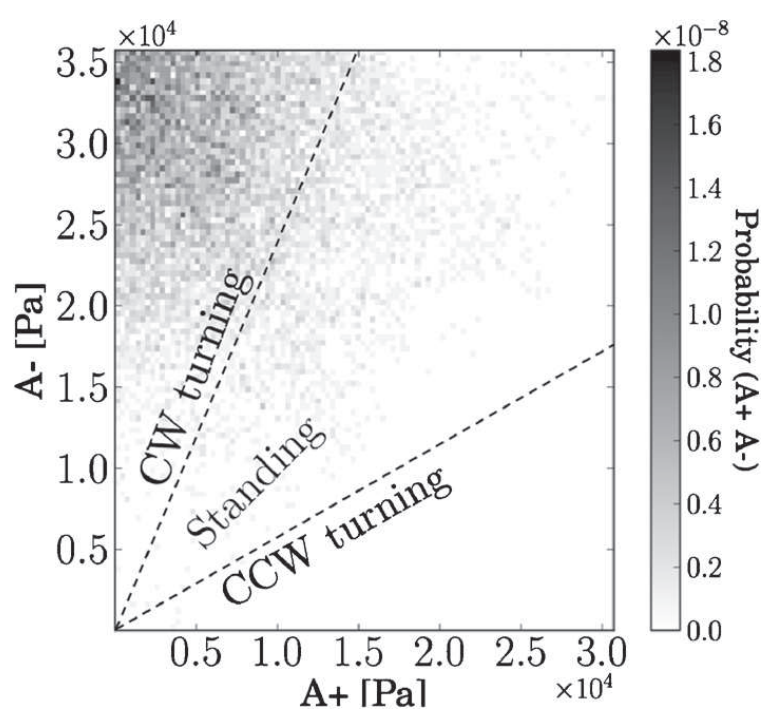


Fig. 16 Middle cut plane with superimposed axial velocity isolines in the range of $-2 \mathrm{~m} / \mathrm{s}$ to $2 \mathrm{~m} / \mathrm{s}$ showing the center recirculation zone dynamics during one oscillation cycle. Instantaneous fields

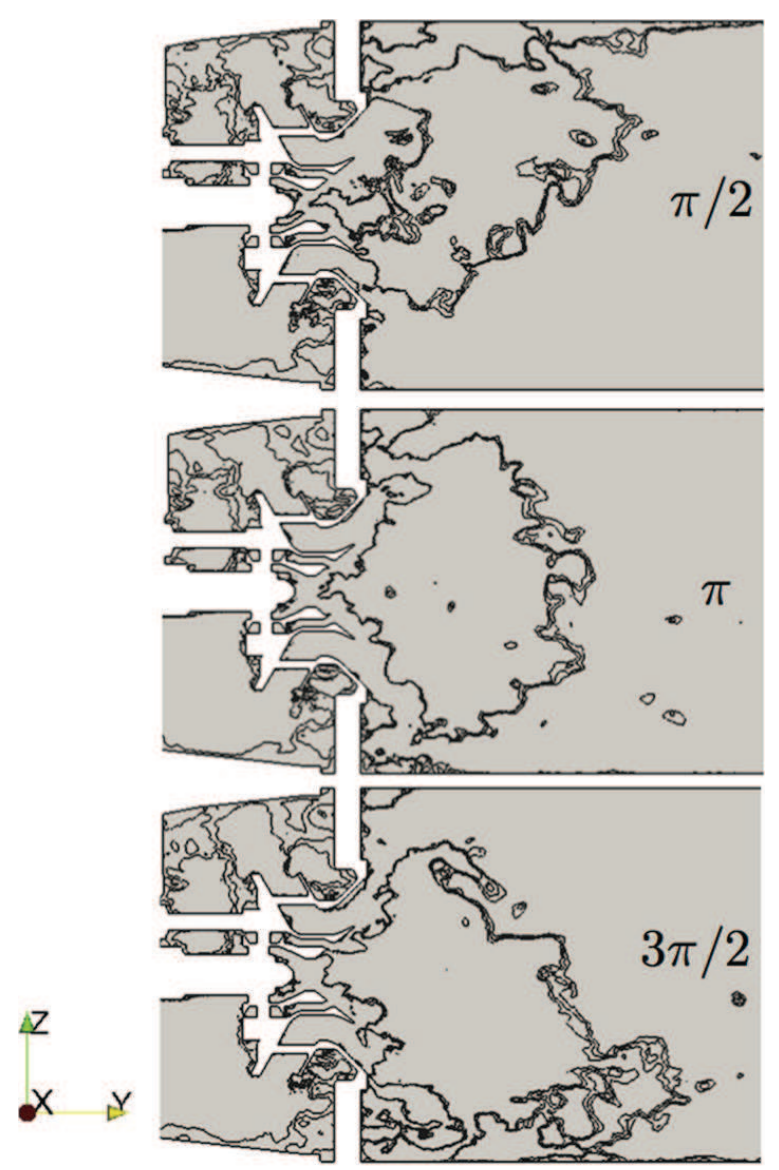

with the acoustic mode leads to a positive Rayleigh index (Fig. 12). This instability driving mechanism was also described theoretically and experimentally in similar experiments $[68,69]$.

Heat release isocontours (Fig. 17 left) indicate that the flame is very long and interacts with lateral walls. The preheated air enhances the evaporation process of fuel injected by the pilot and multipoint injection systems but significant evaporation still takes place near the walls (Fig. 17 right). Therefore, high heat release rates are found at the chamber walls due to fuel accumulation in this region. This seems to be one reason why transverse modes are

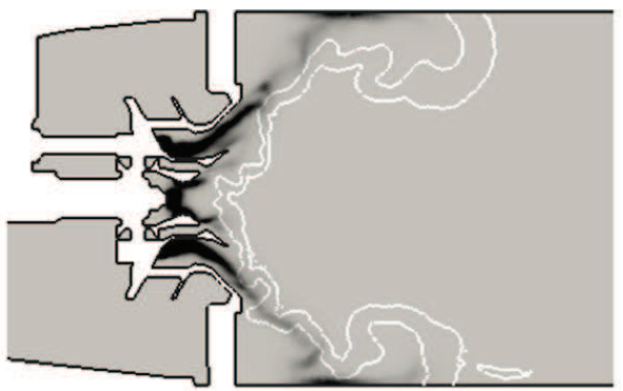

Liquid volume fraction (-)

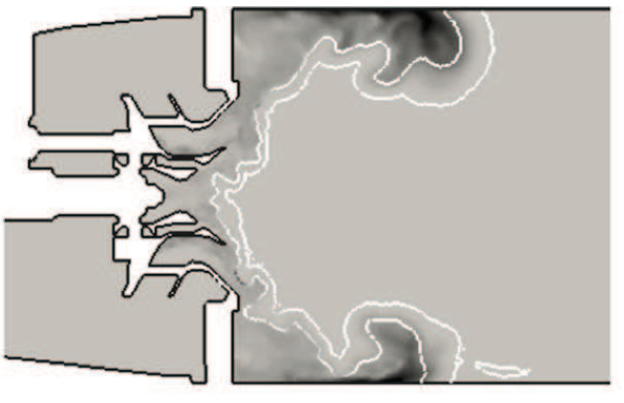

Kerosene (-)

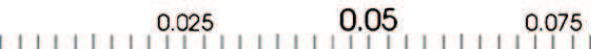

0

Fig. 17 Left: Liquid volume fraction. Right: Kerosene mass fraction. Isoline of heat release $Q=1 e 8 \mathrm{~W}$ superimposed on instantaneous fields 
Fig. 18 Liquid equivalence ratio perturbations caused by the presence of the PVC. Data from probe $P_{P V C}$ in Fig 7

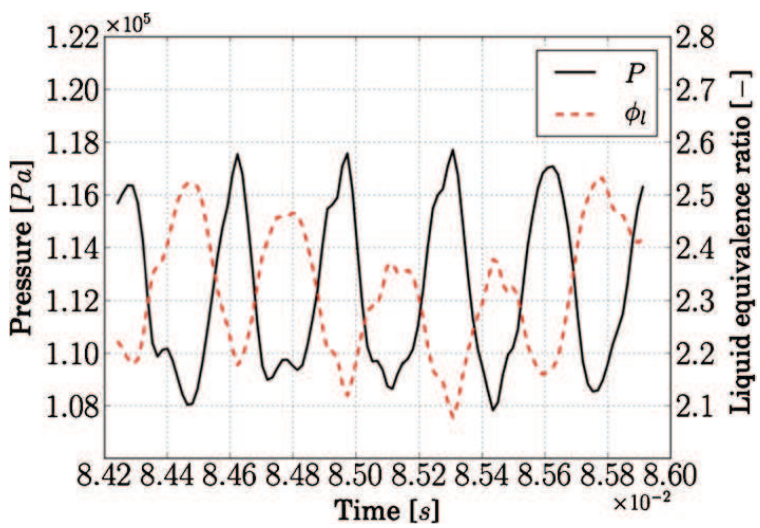

excited as suggested by the Rayleigh index (Fig. 12). The influence of fuel injection placement on transverse pressure oscillations was reported by Marshall et al. [70] who observed high pressure amplitudes when fuel was injected near pressure antinode regions whereas fuel injection near pressure nodes lead to small amplitudes. Figure 13 shows that pressure antinodes are found in the region where most of the fuel is burnt, i.e. at the chamber walls.

Isolines of heat release (Fig. 17) reveal a slightly lifted flame which is not anchored at the pilot injector. In the area between the pilot injector and the flame tip a PVC is found in both non-reacting and reacting cases. It is less intense in the latter case due to combustion induced density stratification which can suppress the PVC formation [71]. The PVC is located here in the first axial swirler stage and exhibits a counter clock-wise $(\mathrm{CCW})$ precession motion and a clockwise winding spiral (Fig. 7). It rotates in the direction of the first swirl stage (Fig. 3 left). It is also impacting the pilot fuel injection (Fig. 18) leading to mixture fraction oscillations.

To understand the interaction between PVC and transverse mode, the LES was repeated with and without damping control. The inlet mass flow rate was changed over a large range while keeping the equivalence ratio of $\phi=0.74$ constant (Table 2). With control, the acoustic field is almost totally inhibited and the PVC frequencies can be determined easily in the absence of acoustic forcing by monitoring velocity fluctuations at probe $P_{P V C}$. Figure 19 displays the evolution of the PVC frequency observed during simulation with control. As expected, the frequency is changing linearly with the mass inflow rate [29, 72]. The corresponding Strouhal number based on the first axial swirler diameter $D_{S}$ and the bulk velocity at the plenum inlet $U_{b u l k}$ is:

$$
S t_{P V C}=\frac{f_{P V C} \cdot D_{S}}{U_{b u l k}}
$$

The Strouhal number is almost constant (of the order of 3) over a wide range of inflow velocities showing that, in the absence of acoustic forcing, a classical CCW turning PVC develops in the chamber [29].

Table 2 LES cases and corresponding mass flow rates

\begin{tabular}{lllllllll}
\hline Case name & L25 & L50 & Base & H05 & H10 & H15 & H50 & H75 \\
\hline Mass flow rate [g/s] & 25 & 50 & 100 & 105 & 110 & 115 & 150 & 175 \\
Norm. mass flow rate & 0.25 & 0.50 & 1 & 1.05 & 1.10 & 1.15 & 1.50 & 1.75 \\
\hline
\end{tabular}

The case named 'Base' is the reference case described in this section and has a normalized mass flow of 1. Case names labeled with ' $L$ ' stand for lower flow rates whereas ' $H$ ' indicates higher flow rates. The normalization flow rate is $100 \mathrm{~g} / \mathrm{s}$ 
Fig. 19 PVC frequencies obtained for different air mass flow rates and corresponding Strouhal number $S t_{P V C}$. The frequencies are determined while using DCWs. The dashed line represents the frequency of the 1T-1L mode $f_{m}$

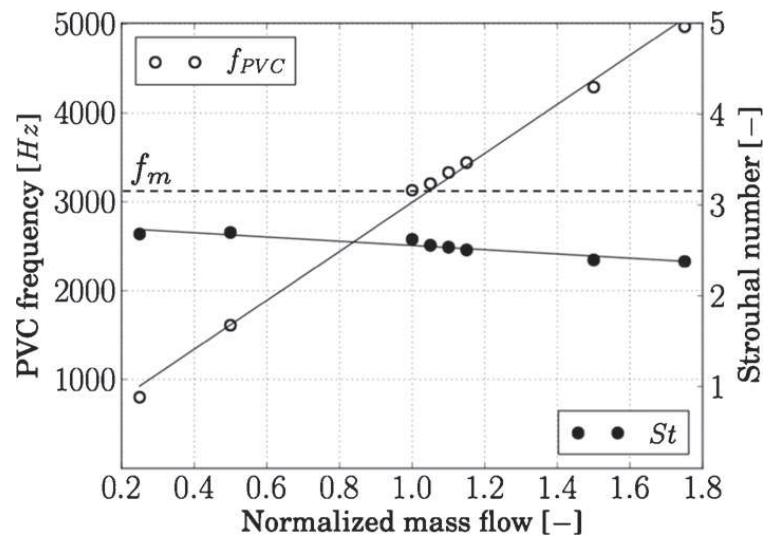

The frequency $f_{m}$ of the acoustic 1T-1L mode obtained in Section 3 is also reported on Fig. 19. It depends very weakly on the flow rate for this subsonic flow. When the normalized flow is close to $1, f_{m}$ matches the natural PVC frequency suggesting that a simple lock-in between acoustic mode frequency $f_{m}$ and PVC frequency $f_{P V C}$ could be the source of the unstable mode even when the frequencies do not match exactly. Hydrodynamic instabilities may exhibit large unstable zones where amplification takes place so it may be sufficient to be in the zone of instability despite a frequency mismatch $[73,74]$. This idea is checked in Fig. 20 which displays the kinetic energy of the orthoradial velocity signal recorded at the point $P_{P V C}$ (Fig. 7) when DCWs are used together with the pressure oscillation amplitude $p_{R M S}^{\prime}$ when rigid walls are used. The kinetic energy of the PVC increases with the flow rate (as observed by Steinberg et al. [24]) but $p_{R M S}^{\prime}$ peaks for a normalized flow rates in the region of 1, confirming that maximum pressure oscillations are obtained when the PVC frequency $f_{P V C}$ matches the acoustic frequency $f_{m}$ of the 1T-1L mode even though the energy of the PVC mode keeps increasing with flow rate. The clockwise turning pressure mode also induces a rotation of the unsteady combustion. Figure 21 displays the normalized heat release signal in each chamber quarter: signals are shifted by a quarter period from each other confirming that the flame turns at the PVC frequency which is also the 1T-1L acoustic frequency.

\section{The T-FTF Model for Transverse Modes in Swirled Combustors}

The previous LES results show that the PVC is an important element of the transverse mode in the present configuration and suggest a model to incorporate this mechanism in a $3 \mathrm{D}$

Fig. 20 PVC energy (recorded with DCWs) and normalized pressure fluctuations (recorded without control) versus normalized mass flow rates

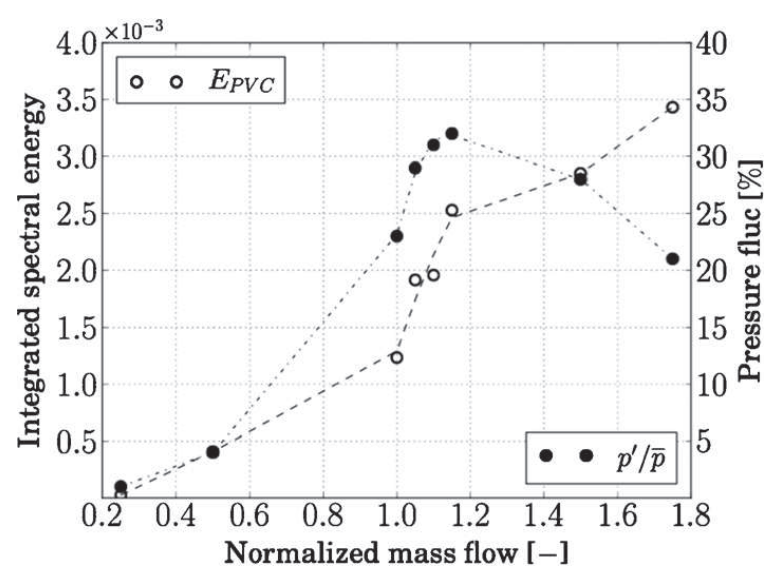


Fig. 21 Rotational nature of the flame with the period for one cycle labels with $\Delta t$

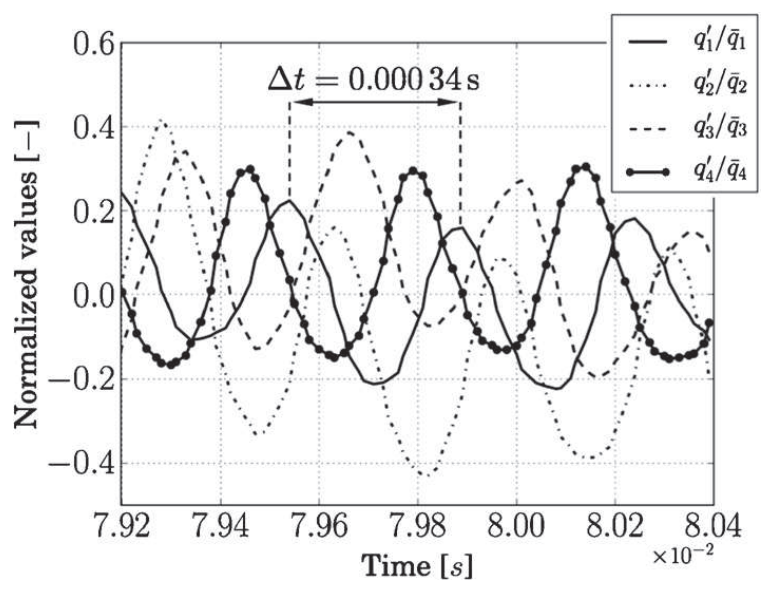

Helmholtz solver. When the local heat release fluctuates $\left(q^{\prime}=\hat{q} e^{-i \omega t}\right)$, the wave equation becomes [33]:

$$
\gamma p_{0} \nabla \cdot\left(\frac{1}{\rho_{0}} \nabla \hat{p}\right)+\omega^{2} \hat{p}=i \omega(\gamma-1) \hat{q}(\mathbf{x})
$$

On the right hand side, a model for the heat release fluctuations $\hat{q}(\mathbf{x})$ is used:

$$
\hat{q}(\mathbf{x})=n(\mathbf{x}) \hat{\mathbf{u}}\left(\mathbf{x}_{r e f}\right) \cdot \mathbf{n}_{r e f} e^{i \omega \tau(\mathbf{x})}
$$

This flame representation is known as a flame transfer function (FTF), which describes flame-flow interactions by an interaction index $n(\mathbf{x})$ and a time delay $\tau(\mathbf{x})$. The quantities $\mathbf{x}_{r e f}$ and $\mathbf{n}_{r e f}$ stand for the reference point and associated unit vector used to relate the unsteady heat release $\hat{q}(\mathbf{x})$ to the acoustics in the combustor. The local amplitude of flame response $n(\mathbf{x})\left[\mathrm{J} / \mathrm{m}^{4}\right]$ and the local time delay of flame response to velocity perturbation $\tau(\mathbf{x})[s]$ in Eq. 6 control the system stability.

Equation 6 has been used extensively for longitudinal acoustic modes where $\hat{u}\left(\mathbf{x}_{r e f}\right)$ measures the unsteady flow rate entering the combustor. Here, we propose an extension for transverse modes where the local heat release perturbations are driven by orthoradial velocity fluctuations and not axial velocities as assumed for longitudinal modes. Use both tangential and radial velocity components for transverse mode prediction was already suggested by Reardon et al. [75] for rocket engines where no swirl was encountered. This approach is suggested by the LES results (Fig. 22) where the axial velocity perturbation shows poor correlation with the heat release fluctuations for this case and a clear one

Fig. 22 Time signals of normalized axial velocity $u_{x}^{\prime}$, orthoradial velocity $u_{\theta}^{\prime}$ and heat release fluctuations $q^{\prime}$ measured at probe $P_{2}$. The time delay is determined as $\tau_{0}=1 e-4 \mathrm{~s}$

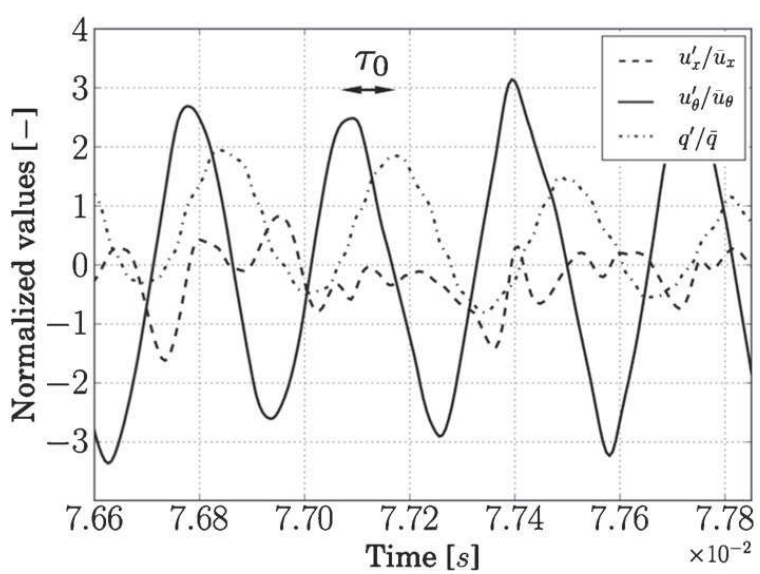




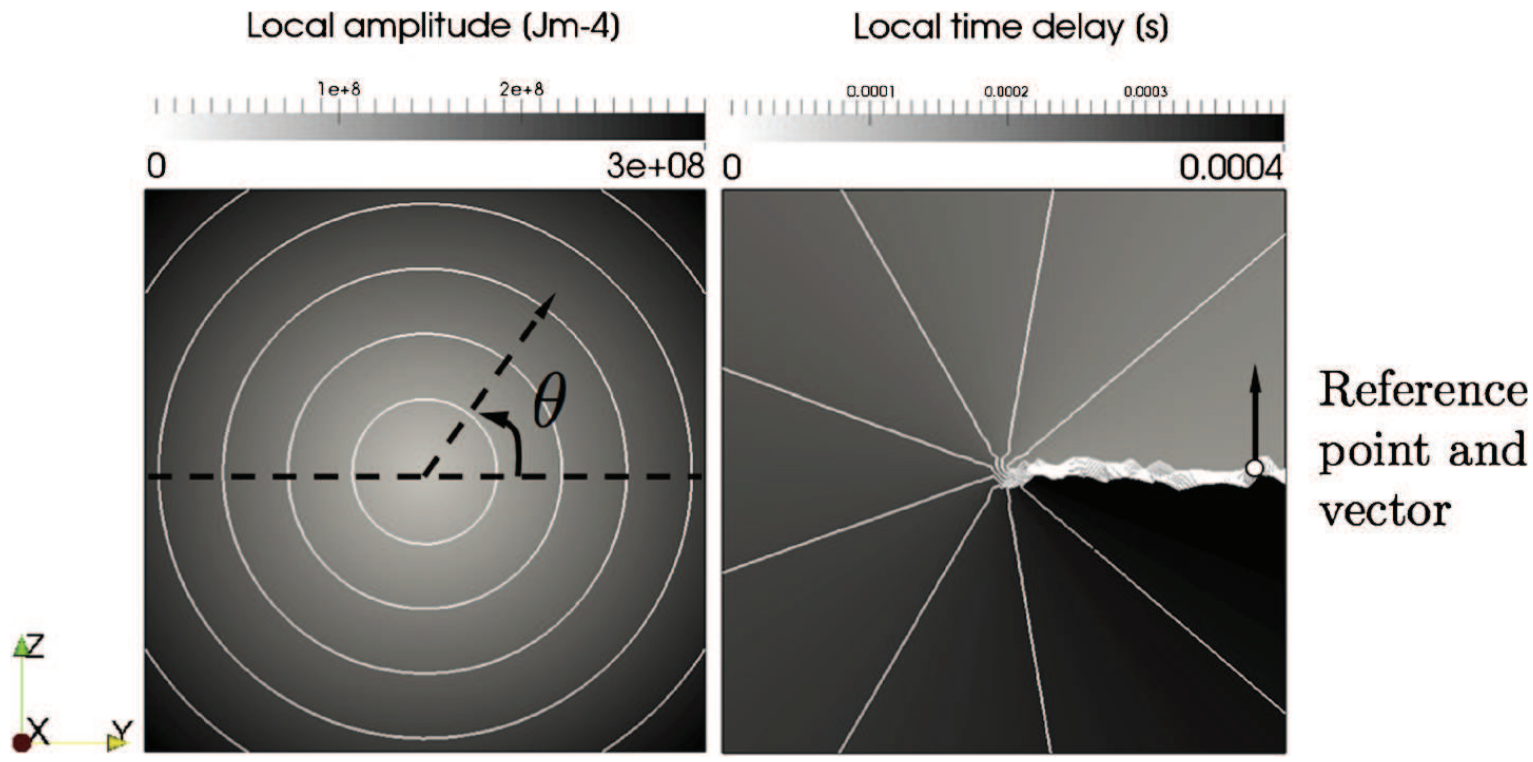

Fig. 23 Left: Local amplitude. Right: Local time delay. Plane A in the chamber (Fig. 1)

with the orthoradial velocity $v_{\theta}$. An appropriate flame representation can be introduced by modifying Eq. 6, so that:

$$
\hat{q}(\mathbf{x})=n(\mathbf{x}) \hat{u}_{\theta}\left(\mathbf{x}_{r e f}\right) \cdot \mathbf{n}_{r e f} e^{i \omega \tau_{\theta}(\mathbf{x})}
$$

where the time delay $\tau_{\theta}(\mathbf{x})$ is imposed as a rotating field:

$$
\tau_{\theta}(\mathbf{x})=\tau_{0}+\frac{\theta}{\omega_{P V C}}
$$

where $\theta$ is the rotation angle (Fig. 23 left). Equation 8 essentially recognizes that the unsteady heat release field rotates at a speed controlled by the hydrodynamic instability as shown in Fig. 21. The time delay between the orthoradial velocity and the unsteady heat release at the same point is denoted as $\tau_{0}$. It is determined from Fig. 22 to $\tau_{0}=1 e-4 \mathrm{~s}$. Note that any reference point can be used in the T-FTF model: using an other point would only lead to a different time $\tau_{0}$ but would not change the results of the acoustic solver. The frequency of the PVC obtained with the DCWs is used in the model: $\omega_{P V C}=2 \pi \cdot f_{P V C}=$ $2 \pi \cdot S t_{P V C} \cdot U_{\text {bulk }} / D_{s}$ and depends on the bulk velocity $U_{b u l k}$. The resulting fields (interaction index and time delay) are plotted in Fig. 23 by visualizing these quantities in plane A (Fig. 1). A radially increasing local amplitude is applied while approaching the combustor

Fig. 24 Stability map of the 1T-1L-2T mode as a function of normalized mass flow rate obtained using acoustic analysis and the T-FTF model

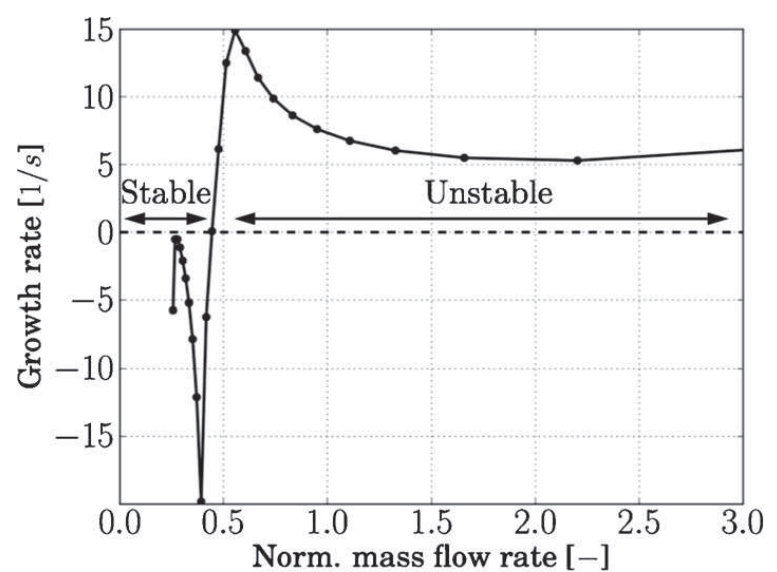


walls: the shape of the $\mathrm{n}$ field plays a limited role on the results. The integrated interaction index over the flame volume is $N_{3}=0.11$ and is obtained from the signals of Fig. 22.

When Eqs. 7 and 8 are used in the Helmholtz solver, the frequency and the growth rate of the 1T-1L mode can be plotted as a function of the combustor flow rate. Results (Fig. 24) show that the 1T-1L mode growth rate is positive when the normalized flow rate is above 0.5. These results are coherent with LES observations (Figs. 19 and 20) where pressure fluctuations reach $5 \%$ of the mean chamber pressure for case L50 (Table 2). The results suggest that the T-FTF formulation of Eq. 8 can be used in a 3D Helmholtz solver to predict transverse modes. Unlike acoustic simulations where no active flame (Section 3) is used, the mode captured with the T-FTF model is non-degenerate: only one mode appears in the acoustic solver. It is a turning mode and its structure matches the 1T-1L-T2 mode seen in the LES.

\section{Conclusion}

This paper studies high-frequency $(3075 \mathrm{~Hz})$ transverse modes appearing in the LES of a swirled kerosene/air combustor operating at atmospheric pressure. These intense nonlinear oscillations $(180 \mathrm{~dB})$ appear in a limited range of flow rates. A damping control technique was implemented in LES by using compliant lateral chamber walls in order to mitigate the acoustic activity while letting the hydrodynamic mode develop. This allowed to measure the frequency of the PVC (Precessing Vortex Core) mode in the absence of acoustic coupling and to show that the strongest resonances (without control) were obtained when the frequency of the PVC (which changes with flow rate) matched the frequency of the 1T$1 \mathrm{~L}$ transverse mode of the chamber. A Flame Transfer Model called T-FTF was developed from the LES observations to capture the transverse mode in a Helmholtz solver. The TFTF model links local heat release fluctuations to orthoradial velocity perturbations. The results suggest that an extended model like the one used here could predict the dynamics of a swirling spray flame and reproduce the stability map obtained by LES when used in the acoustic solver.

\section{References}

1. Lieuwen, T., Yang, V.: Combustion instabilities in gas turbine engines. Operational experience, fundamental mechanisms and modeling. In: Prog. in Astronautics and Aeronautics AIAA, vol. 210 (2005)

2. Culick, F.E.C., Kuentzmann, P.: Unsteady Motions in Combustion Chambers for Propulsion Systems. NATO Research and Technology Organization (2006)

3. Polifke, W., Poncet, A., Paschereit, C.O., Doebbeling, K.: J. Sound Vib. 245(3), 483 (2001)

4. Poinsot, T., Veynante, D.: Theoretical and Numerical Combustion, 3rd edn. (www.cerfacs.fr/elearning) (2011)

5. Kedia, K., Altay, H., Ghoniem, A.: Proc. Combust. Inst. 33, 1113 (2011)

6. Palies, P., Durox, D., Schuller, T., Candel, S.: Combust. Flame 158(10), 1980 (2011)

7. Srinivasan, S., Ranjan, R., Menon, S.: Flow Turbul. Combust. 94(1), 237 (2015)

8. Krebs, W., Flohr, P., Prade, B., Hoffmann, S.: Combust. Sci. Tech. 174, 99 (2002)

9. Wolf, P., Balakrishnan, R., Staffelbach, G., Gicquel, L.Y., Poinsot, T.: Flow Turbul. Combust. 88(1-2), 191 (2012)

10. Worth, N., Dawson, J.: Proc. Combust. Inst. 34, 1 (2012)

11. Bourgouin, J., Durox, D., Moeck, J.P., Schuller, T., Candel, S.: ASME Turbo Expo 2013 GT2013-95010 (2013)

12. Moeck, J., Paul, M., Paschereit, C.: ASME Turbo Expo 2010 GT2010-23577 (2010) 
13. O’Connor, J., Acharya, V., Lieuwen, T.: Prog. Energy Comb. Sci. 49, 1 (2015)

14. Rogers, D.E., Marble, F.E.: J. Prop. 26, 456 (1956)

15. Jourdain, G., Eriksson, L.E.: ISABE-2011-1113 (2011)

16. Selle, L., Benoit, L., Poinsot, T., Nicoud, F., Krebs, W.: Combust. Flame 145(1-2), 194 (2006)

17. Richecoeur, F., Scouflaire, P., Ducruix, S., Candel, S.: Combust. Flame 22(4), 790 (2006)

18. O'Connor, J., Lieuwen, T.: Combust. Sci. Tech. 183(5), 427 (2011)

19. Baillot, F., Blaisot, J.B., Boisdron, G., Dumouchel, C.: J. Fluid Mech. 640, 305 (2009)

20. Zellhuber, M., Meraner, C., Kulkarni, R., Polifke, W., Schuermans, B.: J. Eng. Gas Turbines Power 135(9), 091508 (2013)

21. Apeloig, J.: Étude expérimentale du rôle de la phase liquide dans les phénomènes d'instabilités thermoacoustiques agissant au sein de turbomachines. Ph.D. thesis, Toulouse ISAE (2013)

22. Moeck, J.P., Bourgouin, J.F., Durox, D., Schuller, T., Candel, S.: Combust. Flame 159(8), 2650 (2012)

23. Terhaar, S., Oberleithner, K., Paschereit, C.: Proc. Combust. Inst. 35(3), 3347 (2015)

24. Steinberg, A., Arndt, C., Meier, W.: Proc. Combust. Inst. 34(2), 3117 (2013)

25. Steinberg, A., Boxx, I., Stöhr, M., Carter, C., Meier, W.: Combust. Flame 157(12), 2250 (2010)

26. Paschereit, C.O., Gutmark, E., Weisenstein, W.: AIAA J. 38(6), 1025 (2000)

27. Stöhr, M., Boxx, I., Carter, C.D., Meier, W.: Combust. Flame 159(8), 2636 (2012)

28. Candel, S., Durox, D., Schuller, T., Bourgouin, J.F., Moeck, J.: Ann. Rev. Fluid Mech. 46, 174 (2014)

29. Syred, N.: Prog. Energy Comb. Sci. 32, 93 (2006)

30. Lang, W., Poinsot, T., Candel, S.: Combust. Flame 70, 281 (1987)

31. Bloxsidge, G., Dowling, A., Hooper, N., Langhorne, P.: AIAA J. 26, 783 (1988)

32. Crocco, L.: J. American Rocket Society 22, 7 (1952)

33. Nicoud, F., Benoit, L., Sensiau, C., Poinsot, T.: AIAA J. 45, 426 (2007)

34. Benoit, L., Nicoud, F.: Int. J. Numer. Meth. Fluids 47(8-9), 849 (2005)

35. Wolf, P., Staffelbach, G., Gicquel, L., Muller, J.D., Poinsot, T.: Combust. Flame 159(11), 3398 (2012)

36. Worth, N.A., Dawson, J.R.: Combust. Flame (2013, submitted)

37. Poinsot, T., Candel, S.: J. Comput. Phys. 62, 282 (1986)

38. Poinsot, T., Lele, S.: J. Comput. Phys. 101(1), 104 (1992)

39. Moureau, V., Lartigue, G., Sommerer, Y., Angelberger, C., Colin, O., Poinsot, T.: J. Comput. Phys. 202(2), 710 (2005)

40. Schönfeld, T., Rudgyard, M.: AIAA J. 37(11), 1378 (1999)

41. Selle, L., Lartigue, G., Poinsot, T., Koch, R., Schildmacher, K.U., Krebs, W., Prade, B., Kaufmann, P., Veynante, D.: Combust. Flame 137(4), 489 (2004)

42. Colin, O., Rudgyard, M.: J. Comput. Phys. 162(2), 338 (2000)

43. Ducros, F., Nicoud, F., Poinsot, T.: In: Baines M.J. (ed.) ICFD, pp. 293-300 (1998)

44. Franzelli, B., Riber, E., Sanjosé, M., Poinsot, T.: Combust. Flame 157(7), 1364 (2010)

45. Luche, J., Reuillon, M., Boettner, J.C., Cathonnet, M.: Combust. Sci. Tech. 176, 1935 (2004)

46. Simonin, O., Zaichik, L.I., Alipchenkov, V.M., Février, P.: Phys. Fluids 18, 125107 (2006)

47. Février, P., Simonin, O., Squires, K.: J. Fluid Mech. 533, 1 (2005)

48. Sanjosé, M., Lederlin, T., Gicquel, L., Cuenot, B., Pitsch, H., García-Rosa, N., Lecourt, R., Poinsot, T.: In: CTR (ed.) Proceedings of the Summer Program 2008, pp. 251-263 (2008)

49. Jaegle, F., Senoner, J.M., Garcia, M., Bismes, F., Lecourt, R., Cuenot, B., Poinsot, T.: Proc. Combust. Inst. 33, 2099 (2011)

50. Pascaud, S.: Vers la simulation aux grandes échelles des écoulements turbulents diphasiques réactifs: application aux foyers aéronautiques. Phd thesis, INP Toulouse. http://www.cerfacs.fr/cfdbib/repository/ TH_CFD_06_44.pdf (2006)

51. Hannebique, G., Sierra, P., Riber, E., Cuenot, B.: Flow Turbul. Combust. 90(2), 449 (2013)

52. Vié, A., Jay, S., Cuenot, B., Massot, M.: Flow Turbul. Combust. 90(3), 545 (2013)

53. Druzhinin, O., Elghobashi, S.: J. Fluid Mech. 429, 23 (2001)

54. Colin, O., Ducros, F., Veynante, D., Poinsot, T.: Phys. Fluids 12(7), 1843 (2000)

55. Schmitt, P., Poinsot, T., Schuermans, B., Geigle, K.P.: J. Fluid Mech. 570, 17 (2007)

56. Sengissen, A., Kampen, J.F.V., Huls, R., Stoffels, G., Kok, J.B.W., Poinsot, T.: Combust. Flame 150, 40 (2007)

57. Charlette, F., Meneveau, C., Veynante, D.: Combust. Flame 131(1), 159 (2002)

58. Nicoud, F., Baya Toda, H., Cabrit, O., Bose, S., Lee, J.: Phys. Fluids 23(8), 085106 (2011). doi:10.1063/1.3623274. http://link.aip.org/link/?PHF/23/085106/1

59. Selle, L., Nicoud, F., Poinsot, T.: AIAA J. 42(5), 958 (2004)

60. Berkooz, G., Holmes, P., Lumley, J.L.: Ann. Rev. Fluid Mech. 25(1), 539 (1993)

61. Oberleithner, K., Sieber, M., Nayeri, C., Paschereit, C., Petz, C., Hege, H.C., Noack, B., Wygnanski, I.: J. Fluid Mech. 679, 383 (2011) 
62. Schmid, P.J.: J. Fluid Mech. 656(1), 5 (2010)

63. Motheau, E., Nicoud, F., Poinsot, T.: J. Fluid Mech. 749, 542 (2014)

64. Rienstra, S., Hirschberg, A.: Eindhoven University of Technology (2004)

65. Rayleigh, L.: The Theory of Sound. Mac Millan (reprinted by Dover New York, 1945) (1894)

66. Nicoud, F., Poinsot, T.: Combust. Flame 142, 153 (2005)

67. OConnor, J., Lieuwen, T.: Phys. Fluids (1994-present) 24(7), 075107 (2012)

68. Schwing, J., Grimm, F., Sattelmayer, T.: ASME Turbo Expo 2012: Turbine Technical Conference and Exposition, pp. 553-566. American Society of Mechanical Engineers (2012)

69. Schwing, J., Sattelmayer, T.: ASME Turbo Expo 2013: Turbine Technical Conference and Exposition, pp. V01AT04A003-V01AT04A003. American Society of Mechanical Engineers (2013)

70. Marshall, W., Pal, S., Woodward, R., Santoro, R., Smith, R., Xia, G., Sankaran, V., Merkle, C.: 44th Aerospace Sciences Meeting and Exhibit. AIAA 2006-538 (2006)

71. Oberleithner, K., Terhaar, S., Rukes, L., Paschereit, C.O.: J. Eng. Gas Turbines Power 135(12), 121506 (2013)

72. Anacleto, P., Fernandes, E., Heitor, M., Shtork, S.: Combust. Sci. Tech. 175(8), 1369 (2003)

73. Charru, F.: Hydrodynamic Instabilities, Cambridge Texts in Applied Mathematics. Cambridge University Press (2011)

74. Drazin, P.G., Reid, W.H.: Hydrodynamic Stability. Cambridge University Press, London (1981)

75. Reardon, F., Crocco, L., Harrje, D.: AIAA J. 2(9), 1631 (1964) 